\title{
Natural Ecological Background of Terrestrial Vegetation in China: Identification Methods and Spatial Differentiation Characteristics
}

\author{
Peng Hou, Yan Chen, ${ }^{*}$ Jun Zhai, ${ }^{* *}$ Jing Hou, Min Yang, \\ Diandian Jin, Hanshou Zhu, Haifeng Gao, Huawei Wan, and Zhuo Fu \\ Satellite Application Center for Ecology and Environment, Ministry of Ecology and Environment, \\ Haidian District, Beijing 100094, China
}

(Received September 25, 2021; accepted December 23, 2021)

Keywords: natural ecological background, evaluation of conservation and restoration effectiveness, terrestrial ecosystems, forest, grassland

The closeness of the value of regional ecological parameters to the value of the natural ecological background can be used to efficiently evaluate the effectiveness of vegetation protection and ecological restoration. Advances in remote sensing technology have promoted the use of terrestrial ecosystem parameters obtained by multispectral sensors to identify the ecological background. Therefore, it is important to identify and construct the natural ecological background. By considering the authenticity of nature reserve ecosystems and the spatial differentiation of vegetation ecosystems, in this study we established an identification method for the natural ecological background of vegetation predicated upon a complete geographical unit. In China, land is divided into 106 regions based on different ecosystem functions. Additionally, 292 national nature reserves have been established throughout the country to conserve unique forest and grassland ecosystems. Using the spatial relationship between ecological function regions and the national nature reserves, ecological units of the natural ecological background were identified. The natural ecological background included two types of ecosystems: forest and grassland. It was composed of the current background, recovery rate background, and stability background, including four vegetation parameters that can effectively reflect the vegetation function and community structure: gross primary productivity (GPP), net primary productivity (NPP), leaf area index (LAI), and fractional vegetation cover (FVC). The spatial characteristics of the natural ecological background based on this method were clearly observed. These spatial characteristics are consistent with the ecosystem types and their combination characteristics, the soil and water conditions required for vegetation growth, and the corresponding ecosystem services. Therefore, the findings hold certain objectivity, have a scientific basis, and can be used as a reference for evaluating the effectiveness of terrestrial ecosystem protection and restoration in China.

\footnotetext{
*Corresponding author: e-mail: chenyan30033@163.com

${ }^{* *}$ Corresponding author: e-mail: zhaijunsec@163.com https://doi.org/10.18494/SAM.2021.3664
} 


\section{Introduction}

Environmental threats, such as biodiversity loss, climate disruption, and increasing pollution, have imposed unprecedented pressure on the natural ecosystem; additionally, their negative impacts on the development of human society are increasing. ${ }^{(1-8)}$ To restore damaged ecosystems and improve their capacities to support the sustainable development of human society, the United Nations launched the UN Decade on Ecosystem Restoration in 2021 with the aim of achieving the global mission of "restoring billions of hectares of ecosystem" and changing the mission "from developing nature to curing nature."

After more than 60 years of unremitting efforts, ecological protection and restoration in China have changed from rescue protection to systematic protection; additionally, the previous single type of ecosystem protection has been modified into overall ecosystem protection. Furthermore, the restoration of terrestrial ecosystems has undergone a transformation from the restoration and mitigation of specific ecological problems to the restoration and mitigation of single-type ecosystems, and finally to the systematic mitigation of ecological protection and restoration problems of mountains, rivers, forests, farmland, lakes, and grassland. The mode of ecosystem restoration has also changed from artificial restoration to natural restoration supplemented by artificial restoration. ${ }^{(9-13)}$ Such diversified measures can help achieve the goal of protecting ecosystems with important value, improving the ecosystem quality, and restoring the original ecosystem functions. ${ }^{(14-25)}$ To achieve more efficient restoration results, it is necessary to continuously improve and optimize ecological protection and restoration measures through scientific and accurate evaluation of the effectiveness of current measures. Presently, in addition to scientific evaluation methods, establishing a natural ecological background system has become a key hotspot of scientific research to judge the effect of ecological protection and restoration. ${ }^{(26)}$ Therefore, the problem to be solved in this study is how to establish a natural ecological background for the evaluation of ecological protection and restoration effects.

Natural background values reflect the environmental quality of the original condition, which refers to the basic chemical composition of various environmental elements, such as water, the atmosphere, biotic components, rock, soil, and other chemical elements, without the influence of human activities. ${ }^{(27)}$ In 2002, the National Environmental Protection Agency defined the background values as the concentrations of substances in the case of no anthropogenic impact, and the background is usually divided into natural and anthropogenic background values. ${ }^{(28)}$ Research on background values has important theoretical and practical significance at the national and international levels. Several countries have studied background values, mostly in soil and aquatic environments. ${ }^{(29-36)}$ To evaluate the applications of ecological background values, the ecological background is mainly constructed by studying the natural vegetation and the native vegetation during historical periods along with the regional ecological pressure and carrying capacity. ${ }^{(37-41)}$

Vegetation is the most important biological community in terrestrial ecosystems. ${ }^{(42,43)}$ The quality of vegetation growth directly reflects the terrestrial ecosystem quality. ${ }^{(44-46)}$ Therefore, ecological restoration of vegetation is the most intuitive expression of terrestrial ecosystem restoration. Constructing a natural background value system that is composed of vegetation 
ecological parameters is fundamental for evaluating the effectiveness of terrestrial ecosystem restoration. However, human activities have influenced environmental parameters worldwide ${ }^{(47,48)}$ with only few terrestrial ecosystems on Earth that can be regarded as having background values without any influences of human development and utilization.

In China, all nature reserves are established, managed, and maintained by the government. Tourists and locals are not permitted in the core zone of nature reserves; tourism, production, and operation activities are prohibited in the buffer zone; and tourism is permitted in the experimental area only after the management objectives of the nature reserve are satisfied. ${ }^{(49-51)}$ Therefore, owing to these strict management measures, nature reserves efficiently preserve the original ecosystem and are the areas closest to the natural ecological background of vegetation in China.

Vegetation types and their distribution are affected by many natural geographical factors, such as regional topography and climate conditions; thus, they show evident spatial differentiation characteristics worldwide. ${ }^{(52-54)}$ Conventionally, the regional vegetation status was mainly acquired through a limited number of observation points. However, with the development of satellite-based remote sensing technology, the regional vegetation status can be described quantitatively in a more efficient manner.

In view of this, the aim of this study was to identify and establish the natural ecological background system of land vegetation according to the ecological status of national and provincial nature reserves using land vegetation parameters acquired through remote sensing and according to the principle of ecosystem function zoning and classification. Additionally, the spatial differentiation characteristics of the ecosystem were analyzed. This study provides a reference for the evaluation of terrestrial ecosystem protection and restoration effects.

\section{Methods and Data}

\subsection{Research method}

By considering the authenticity of nature reserve ecosystems and the spatial differentiation of vegetation ecosystems, we established an identification method for the natural ecological background of vegetation based on a complete geographical unit. The conceptual model is shown in Fig. 1. First, with the goal of protecting and restoring ecosystems and improving ecosystem service capacity, the overlap and inclusion relationships between 106 ecological function regions and 292 national nature reserves, and the spatial basis of the natural ecological background, an "ecological homogeneous area", was constructed. Subsequently, the vegetation ecological background of natural geographical units, where the nature reserve was classified by region and type, was identified by considering the vegetation characteristics of the nature reserved as the background, based on the time dimension of "Recovery-Stability" and the type dimension of "Forest and Grassland" of vegetation. Natural ecological background indicators of the system included common background value $(C B V)$, recovery background value $(R B V)$, and stability background value $(S B V)$. The main parameters representing vegetation (gross primary productivity (GPP), net primary productivity (NPP), leaf area index (LAI), and fractional vegetation cover $(\mathrm{FVC})$ formed the index parameters used in this study. 


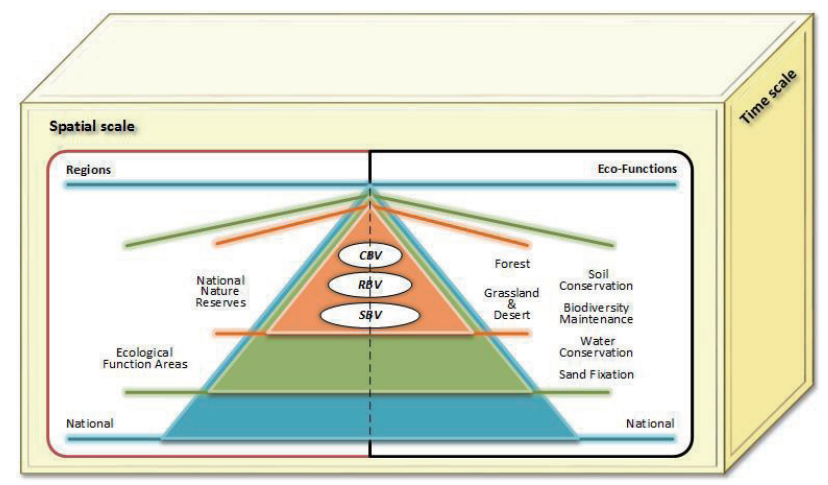

Fig. 1. (Color online) Conceptual model for the identification of terrestrial ecological background of vegetation.

\subsubsection{Determination of ecological region}

Natural ecological background zoning was performed on the basis of the superposition relationship between the national nature reserves and national ecological function zoning.

First, among all national nature reserves, 272 forest-type nature reserves and 20 grasslandtype nature reserves were selected. Thus, 292 national nature reserves of vegetation ecological types were considered in total as the natural ecological background for vegetation.

Second, based on the National Ecological Function Region (revised edition) ${ }^{(55)}$ jointly issued by the Ministry of Ecology and Environment, PRC, and the Chinese Academy of Sciences in 2015, 41 water conservation function areas, 31 biodiversity maintenance function areas, 19 soil conservation function areas, and 15 sand fixation function areas were selected as vegetation ecological regions.

Finally, based on the spatial overlap and inclusion relationships of the above two types of areas and the differences in the protection objectives, the types of ecological function areas were distinguished, and the natural ecological background regions were constructed. Nature reserves are small and scattered, while ecological function areas are more extensive than those of nature reserves. National nature reserves and national ecological function regions are adjacent to each other. Furthermore, the nature reserves distributed in each ecological function region were analyzed. Forests and grassland were the ecological function regions for the forest and grassland ecosystem nature reserves, respectively. In the presence of both forest and grassland nature reserves in the ecological function region, the nature type was determined according to the ecological functions of the respective reserve area.

To ensure the integrity of the natural ecological background for important ecological function areas without any natural reserves, the functional regions with the distribution of protected areas with similar natural ecological conditions should be selected according to their natural conditions and ecosystem functions, and the same background value should be allotted while identifying the ecological background. All background divisions included the key areas with various ecosystem functions in China. The forest ecological background included all four types of ecological function regions, and the grassland ecological background included three ecological function regions (sand fixation, water conservation, and biodiversity protection). To 
facilitate easy expression and application, the natural ecological background regions of forest and grassland ecosystems were coded (Fig. 2, Tables 1 and 2).

\subsubsection{Natural ecological background identification}

The natural ecological background was identified by calculating the current condition, restoration rate, and stability of vegetation status parameters in the nature reserve in each natural ecological background region. The average, slope, and standard deviation of the four main parameters (GPP, LAI, NPP, and FVC) were respectively calculated as $C B V, R B V$, and $S B V$ of the regional vegetation ecosystem.

$C B V$ is the common background of the ecosystem and refers to the regional average value of each parameter (GPP, LAI, NPP, and FVC) in the last 20 years [Eqs. (1) and (2)]. $C B V$ is directly proportional to the productivity of the terrestrial ecosystem in the region.

$$
\begin{aligned}
& C B V=\frac{\sum_{c=1}^{N} \overline{m_{c}}}{N} \\
& \overline{m_{c}}=\frac{\sum_{i=1}^{n}\left(m_{c}\right)_{i}}{n}
\end{aligned}
$$

Here, $\bar{m}_{c}$ is the annual average of GPP, LAI, NPP, and FVC of each pixel in the region, $n$ is the number of years, and $N$ is the number of remote sensing image pixels in the region.

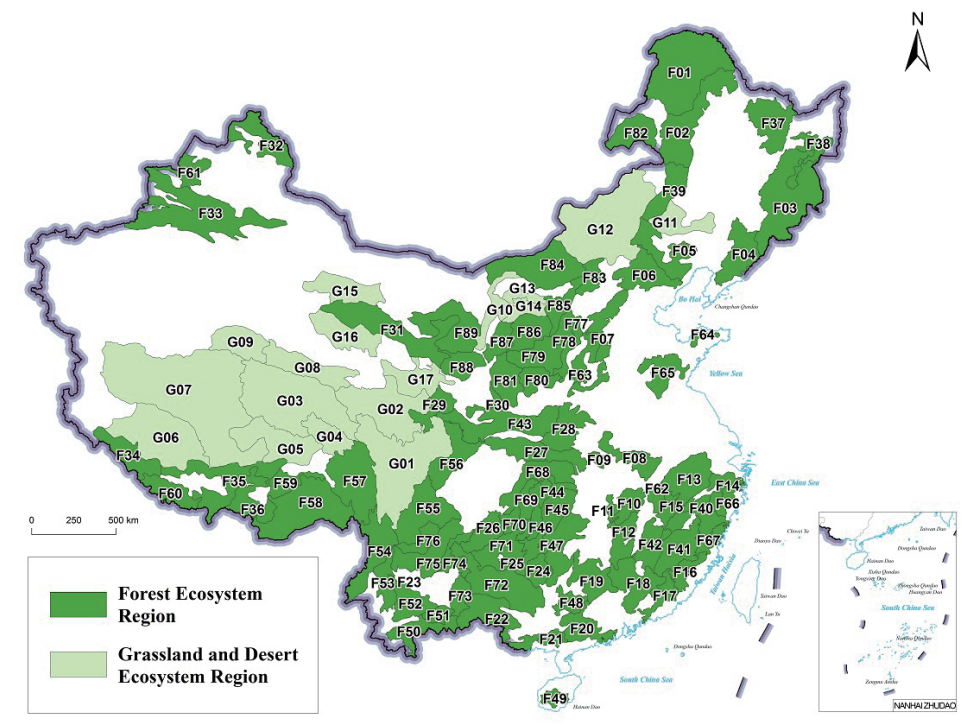

Fig. 2. (Color online) Natural ecological background regions of forest and grassland ecosystems. (The base map is from the standard map (GS (2019)1686) on the website (http://bzdt.ch.mnr.gov.cn/.) and has not been modified. Maps produced from the same source also include Figs. 4, 5, 7, 8, 10, and 11.) 
Table 1

Coding of forest ecological background regions.

\begin{tabular}{|c|c|c|c|c|c|}
\hline Code & Name & $\begin{array}{l}\text { No. of } \\
\text { reserves }\end{array}$ & Code & Name & $\begin{array}{l}\text { No. of } \\
\text { reserves }\end{array}$ \\
\hline F01 & Northern Da Hinggan Mountains WC-EFR & 7 & $\mathrm{~F} 46$ & $\begin{array}{l}\text { Southeast Chongqing-Northeast Guizhou BM-EFR } \\
\text { and SC-EFR }\end{array}$ & 1 \\
\hline F02 & Central Da Hinggan Mountains WC-EFR & 2 & $\mathrm{~F} 47$ & Xuefeng Mount BM-EFR and SC-EFR & 10 \\
\hline F03 & Changbai Mountains WC-EFR & 17 & F48 & Dayao Mountains BM-EFR & 1 \\
\hline F04 & Eastern Liaoning Mountains WC-EFR & 3 & F49 & Central Hainan BM-EFR and WC-EFR & 6 \\
\hline F05 & Liaohe River Source WC-EFR & 7 & F50 & Southern Yunnan BM-EFR & 7 \\
\hline F06 & Northern Beijing-Tianjin-Hebei WC-EFR & 9 & F51 & $\begin{array}{l}\text { Mengzi and Yuanjiang Karst Plateau Canyon BM- } \\
\text { EFR }\end{array}$ & 2 \\
\hline F07 & Taihang Mountains WC-EFR & 7 & F52 & Wuliang Mount-Ailao Mount BM-EFR & 3 \\
\hline F08 & Dabie Mount WC and SC-EFR & 9 & F53 & Western Yunnan Mountains BM-EFR & 1 \\
\hline F09 & Dahong Mountains WC-EFR & 0 & F54 & Northwest Yunnan Plateau BM-EFR and WC-EFR & 5 \\
\hline F10 & Jiuling Mountains WC-EFR & 3 & F55 & Liang Mount BM-EFR & 7 \\
\hline F11 & Mufu Mountains WC-EFR & 0 & F56 & $\begin{array}{l}\text { Minshan Mount-Qionglai Mount BM-EFR and WC- } \\
\text { EFR }\end{array}$ & 7 \\
\hline F12 & Luoxiao Mountains WC-EFR & 4 & F57 & Snowy Mount-Nianta Weng Mount BM-EFR & 2 \\
\hline F13 & $\begin{array}{l}\text { Tianmu Mount-Huaiyu Mount WC-EFR and BM- } \\
\text { EFR }\end{array}$ & 7 & F58 & Shannan Area BM-EFR & 2 \\
\hline F14 & Eastern Zhejiang Hills WC-EFR & 1 & F59 & Southern Nianqing Tanggula Mountain BM-EFR & 0 \\
\hline F15 & Wuyi Mount WC-EFR & 1 & F60 & Mount Qomolangma BM and WC-EFR & 1 \\
\hline F16 & Southern Fujiang Mountains WC-EFR & 2 & F61 & Western Junggar Basin BM-EFR & 1 \\
\hline F17 & $\begin{array}{l}\text { Eastern Guangdong-Western Fujiang Mountains and } \\
\text { Hills WC-EFR }\end{array}$ & 1 & F62 & Poyang Lake BM-EFR & 1 \\
\hline F18 & Jiulian Mount WC-EFR & 5 & F63 & Taiyue Mountains SC-EFR & 1 \\
\hline F19 & Dupang Mount-Mengzhu Mount WC-EFR and SC-EFR & 9 & F64 & Shandong Peninsula Hills SC-EFR & 1 \\
\hline F20 & Yunkaida Mount WC-EFR & 1 & F65 & Middle Shandong Mountains SC-EFR & 0 \\
\hline $\mathrm{F} 21$ & Southeast Guangxi Hills WC-EFR & 0 & F66 & Middle Zhejiang Hills SC-EFR & 0 \\
\hline F22 & Upper Xijiang River WC-EFR and SC-EFR & 8 & F67 & Eastern Fujian Low Mountains and Hills SC-EFR & 1 \\
\hline F23 & Honghe River Source WC-EFR & 1 & F68 & Three Gorges Reservoir Area SC-EFR & 11 \\
\hline $\mathrm{F} 24$ & Southeast Guizhou Northwest Guangxi Hills WC-EFR & 3 & F69 & Southeast Chongqing Mountains SC-EFR & 1 \\
\hline $\mathrm{F} 25$ & Eastern Guizhou Low-Middle Mountain WC-EFR & 2 & F70 & Northern Guizhou Mountain Plateau SC-EFR & 3 \\
\hline F26 & Dalou Mountains WC-EFR and BM-EFR & 4 & F71 & Middle Guizhou Karst SC-EFR & 1 \\
\hline $\mathrm{F} 27$ & Micang Mount-Daba Mount WC-EFR & 10 & F72 & Guizhou Guangxi Karst SC-EFR & 6 \\
\hline F28 & Southeast Henan Mountains WC-EFR & 4 & F73 & Eastern Yunnan SC-EFR & 0 \\
\hline F29 & Southern Gansu Mountains WC-EFR & 3 & F74 & Wumeng Mountains SC-EFR & 1 \\
\hline $\mathrm{F} 30$ & Liupan Mountains WC-EFR and BM-EFR & 1 & F75 & Sichuan Yunan Dry-Hot Valley SC-EFR & 4 \\
\hline $\mathrm{F} 31$ & Qilian Mountains WC-EFR & 3 & F76 & Southwest Sichuan Mountains SC-EFR & 0 \\
\hline $\mathrm{F} 32$ & Altai Mountains WC-EFR and BM-EFR & 1 & F77 & Eastern Lvliang Loess Hill and Gully SC-EFR & 1 \\
\hline F33 & Tianshan Mount WC-EFR and BM-EFR & 2 & F78 & Lvliang Mountains SC-EFR & 4 \\
\hline F34 & Upper Yarlung Zangbo River WC-EFR & 1 & F79 & Northern Shaanxi Loess Hills and Gully SC-EFR & 0 \\
\hline $\mathrm{F} 35$ & Middle Yarlung Zangbo River WC-EFR & 1 & $\mathrm{~F} 80$ & Middle Shanxi Loess Hills and Gully SC-EFR & 3 \\
\hline F36 & North of Middle Himalayan WC-EFR & 0 & F81 & Eastern Gansu-Northern Ningxia SC-EFR & 1 \\
\hline F37 & Xiaoxing'an Mountains BM-EFR & 7 & F82 & Hulun-Beir Grassland SF-EFR & 1 \\
\hline $\mathrm{F} 38$ & Northern Changbai Mountains BM-EFR & 2 & F83 & Yinshan Mountains SF-EFR & 0 \\
\hline F39 & Southern Daxing'an Mountains BM-EFR and WC-EFR & 6 & F84 & Northern Yinshan Mount SF-EFR & 1 \\
\hline $\mathrm{F} 40$ & Zhejiang Fujian Mountains BM-EFR and WC-EFR & 8 & F85 & Eastern Ordos Plateau SF-EFR & 1 \\
\hline $\mathrm{F} 41$ & Wuyi Mount-Daiyun Mount BM-EFR & 11 & F86 & Mu Us Sandy Land SF-EFR & 0 \\
\hline $\mathrm{F} 42$ & Upper Ganjiang River BM-EFR & 0 & F87 & Southwest Ordos Plateau SF-EFR & 2 \\
\hline $\mathrm{F} 43$ & Qinling Mountains BM-EFR and WC-EFR & 18 & F88 & Middle Gansu-Middle Ningxia SF-EFR & 2 \\
\hline F44 & Southwest Hubei BM-EFR & 7 & F89 & Tengger Desert SF-EFR & 1 \\
\hline $\mathrm{F} 45$ & Wuling Mountains BM-EFR & 8 & & & \\
\hline
\end{tabular}

Types of ecological function regions: SC-EFR, soil conservation function regions; BM-EFR, biodiversity maintenance function regions; WC-EFR; water conservation function regions; SF-EFR, sand fixation function regions. 
Table 2

Coding of ecological background regions of grassland.

\begin{tabular}{|c|c|c|c|c|c|}
\hline Code & Name & $\begin{array}{l}\text { No. of } \\
\text { reserves }\end{array}$ & Code & Name & $\begin{array}{l}\text { No. of } \\
\text { reserves }\end{array}$ \\
\hline G01 & Northwest Sichuan WC and BM-EFR & 3 & G10 & $\begin{array}{l}\text { Western Erdos-Helan Mount-Yinshan } \\
\text { Mount BM-EFR }\end{array}$ & 1 \\
\hline G02 & Yellow River Source WC-EFR & 2 & G11 & Horqin Sandy Land SF-EFR & 1 \\
\hline G03 & Yangtze River Source WC-EFR & 4 & G12 & Hunshandak Sandy Land SF-EFR & 1 \\
\hline G04 & Lancang River Source WC-EFR & 1 & G13 & Northern Erdos Plateau SF-EFR & 0 \\
\hline G05 & Nujiang River Source WC-EFR & 1 & G14 & Middle Erdos Plateau SF-EFR & 0 \\
\hline G06 & Southern Qiangtang BM-EFR & 1 & G15 & Western Hexi Corridor SF-EFR & 2 \\
\hline G07 & $\begin{array}{l}\text { Northwest Tibet Qiangtang Plateau } \\
\text { BM-EFR }\end{array}$ & 4 & G16 & $\begin{array}{l}\text { Northeast Qaidam Basin Mountains } \\
\text { SF-EFR }\end{array}$ & 0 \\
\hline G08 & Eastern Kunlun Mount BM-EFR & 3 & G17 & Gonghe Basin SF-EFR & 1 \\
\hline G09 & Southern Altun Mountain BM-EFR & 3 & & & \\
\hline
\end{tabular}

$R B V$ is the background of the ecosystem recovery rate and refers to the recovery trend of the parameters (GPP, LAI, NPP, and FVC) expressed by the regional average of the slope of the linear regression equation of each parameter in the last 20 years [Eqs. (3) and (4)]. $R B V$ is directly proportional to the degree of restoration of the terrestrial ecosystem.

$$
\begin{gathered}
R B V=\frac{\sum_{c=1}^{N} k_{c}}{N} \\
k_{c}=\frac{n \times \sum_{i=1}^{n} \times Q_{i}-\sum_{i=1}^{n} i \sum_{i=1}^{n} Q_{i}}{n \times \sum_{i=1}^{n} i^{2}-\left(\sum_{i=1}^{n} i\right)^{2}}
\end{gathered}
$$

Here, $k_{c}$ is the slope of the parameters (GPP, LAI, NPP, and FVC) of each pixel in the region with its value ranging from -1 to 1 , where $k_{c}>0$ represents a recovery trend, while $k_{c}<0$ shows a deteriorating trend. Furthermore, $Q_{i}$ is the parameter value, $n$ is the number of years, and $N$ is the number of remote sensing image pixels in the region.

$S B V$ is the background of ecosystem stability, which refers to the stability of the regional parameters (GPP, LAI, NPP, and FVC) expressed by the regional average of the multiyear standard deviation of each parameter in the last 20 years [Eqs. (5) and (6)]. SBV is directly proportional to the fluctuation in the terrestrial ecosystem.

$$
S B V=\frac{\sum_{c=1}^{N} s t d_{c}}{N}
$$




$$
s t d_{c}=\sqrt{\frac{\sum_{\mathrm{i}=1}^{n}\left(Q_{i}-\bar{Q}\right)^{2}}{n}}
$$

Here, $s t d_{Q}$ is the multiyear standard deviation of each parameter (GPP, LAI, NPP, and FVC), $\bar{Q}$ is the regional average annual mean value of each parameter, $Q_{i}$ is the parameter value, $n$ is the number of years, and $N$ is the number of remote sensing image pixels in the region.

The national natural ecological background showed clear spatial characteristics. Each natural ecological background region was assigned values according to $C B V, R B V$, and $S B V$ of the four parameters (GPP, NPP, LAI, and FVC), and displayed on a color scale. Three groups of four spatial distribution images from each group were obtained. The spatial characteristics of the natural ecological background were observed through maps as shown in Sect. 3.

\subsection{Data}

Vegetation ecological parameter data were obtained from Global Land Surface Satellite (GLASS) products. ${ }^{(56)}$ GLASS is a long-sequential and high-precision global land surface remote sensing product obtained by inversion based on multisource remote sensing data and groundmeasured data, which include various land surface parameter data products. The datasets of GPP, LAI, NPP, and FVC of the GLASS products from 2000 to 2019 were selected to construct the natural ecological background. All types of parameter data were year-on-year mean grid data with a spatial resolution of $500 \mathrm{~m}$ obtained by splicing and solving the arithmetic mean value based on the standard framing product dataset with a temporal resolution of $8 \mathrm{~d}$. According to the production technology and characteristics of the GLASS products, data pre-processing was conducted for each parameter to remove the filling and abnormal values in the dataset and restore the proportional coefficient.

The boundary of each national nature reserve was acquired from the Ministry of Ecology and Environment, PRC. By 2020, China had established 474 national nature reserves, which were divided into forests, grassland, and meadows; wildlife areas; deserts; inland wetland; marine coasts; and relics. ${ }^{(57)}$ The ecological function regions were selected on the basis of the National Ecological Functional Region (revised edition) published by the Ministry of Ecology and Environment, PRC, and the Chinese Academy of Sciences in 2015. This zoning was proposed with the aims of ecosystem investigation, ecological sensitivity assessment, and ecosystem service evaluation after understanding the law of the ecological spatial distribution and determining the ecological functions of ecosystems, including three categories, nine types, and 242 ecological function areas.

This study referred to China's multiperiod land use land cover remote sensing monitoring dataset ${ }^{(58)}$ to analyze and distinguish the ecological characteristic functional areas of forest and grassland ecosystems. 


\section{Results}

\subsection{Spatial characteristics of $\mathrm{CBV}$}

\subsubsection{Differences in $C B V$ between different ecological functions}

$C B V$ differed with the type of ecological function region (Fig. 3). In general, $C B V$ of forest ecosystems was higher than that of grassland ecosystems.

No difference in $C B V$ of forest ecosystems with the water conservation, biodiversity maintenance, and soil conservation functions was evident, while the ranges of GPP, NPP, LAI, and $\mathrm{FVC}$ were $3.9-4.22$ and $1.91-2.08 \mathrm{kgC} / \mathrm{m}^{2}$ and $2.01-2.22$ and $68.85-72.77 \%$, respectively. In contrast, $C B V$ of forest ecosystems with the sand fixation function was the lowest.

$C B V$ of grassland ecosystems in the biodiversity protection functional area was the lowest with GPP, NPP, LAI, and FVC values of 0.20 and $0.11 \mathrm{kgC} / \mathrm{m}^{2}$ and 0.10 and $1.18 \%$, respectively. The parameter values differed between the water conservation and sand fixation ecological function regions. Overall, $C B V$ of the water conservation ecological function region (GPP $=$ $0.89 \mathrm{kgC} / \mathrm{m}^{2}, \mathrm{NPP}=0.53 \mathrm{kgC} / \mathrm{m}^{2}, \mathrm{LAI}=0.40 \%$, and $\left.\mathrm{FVC}=19.39 \%\right)$ was higher than that of the windbreak and sand fixation ecological function regions (GPP $=0.63 \mathrm{kgC} / \mathrm{m}^{2}, \mathrm{NPP}=$ $0.36 \mathrm{kgC} / \mathrm{m}^{2}, \mathrm{LAI}=0.24 \%$, and $\left.\mathrm{FVC}=10.69 \%\right)$.

\subsubsection{Spatial characteristics of forest ecosystem $C B V$}

This study established $C B V$ of forest ecosystems in China, which showed evident spatial characteristics from the northeast to southwest direction (Fig. 4). High values were observed in the eastern and southern regions, while low values were observed in the western and northern regions.

The forest ecosystem $C B V$ in humid thermal, sub-thermal, and dry karst areas in southern China was the highest, in which the average GPP was $>6 \mathrm{kgC} / \mathrm{m}^{2}$ and the vegetation coverage was $>90 \%$. Tropical rain forests, seasonal rain forests, mountain evergreen broad-leaved forests, primary subtropical evergreen broad-leaved forests, arid evergreen broad-leaved forests, and

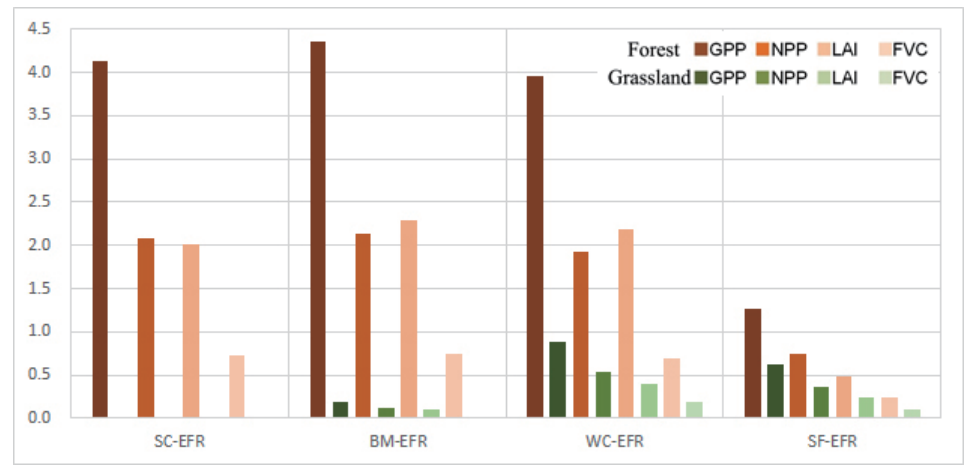

Fig. 3. (Color online) Differences in $C B V$ between the four types of ecological function region. 


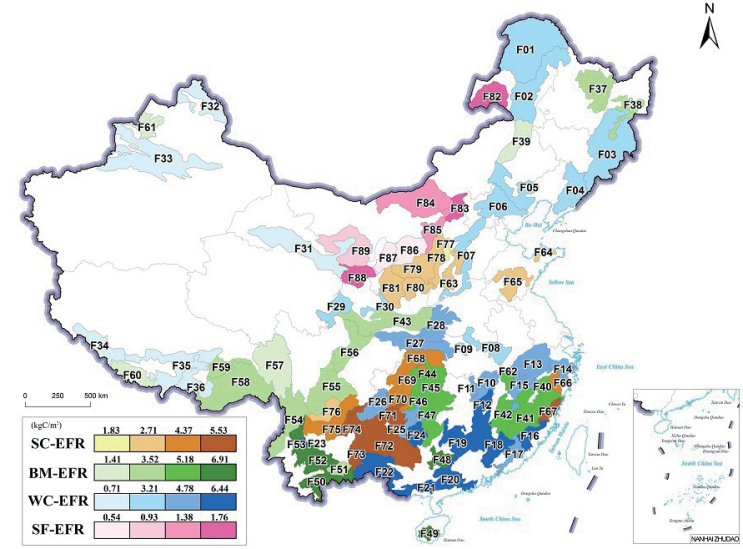

(a)

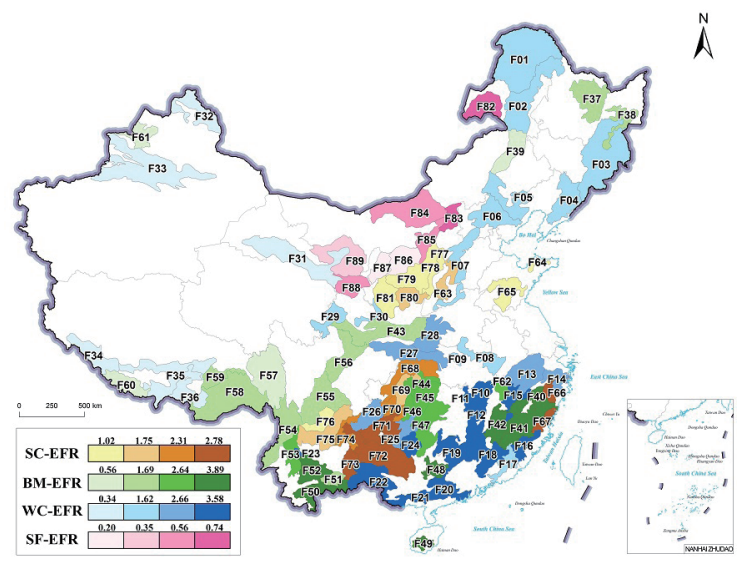

(c)

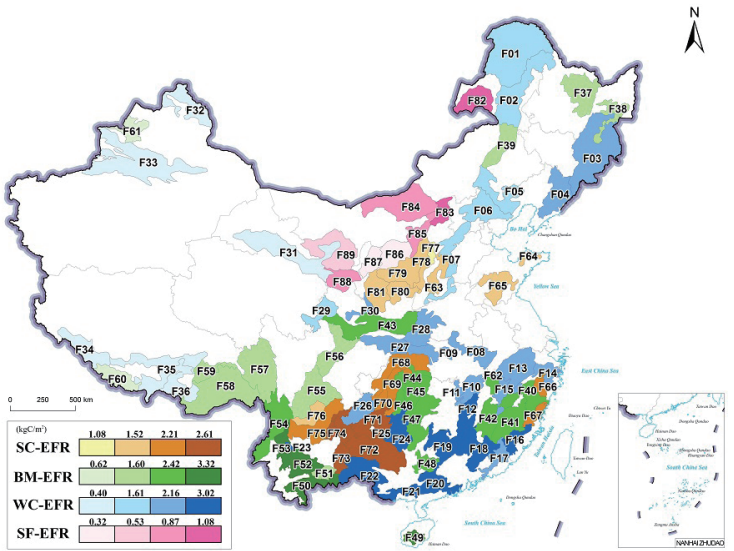

(b)

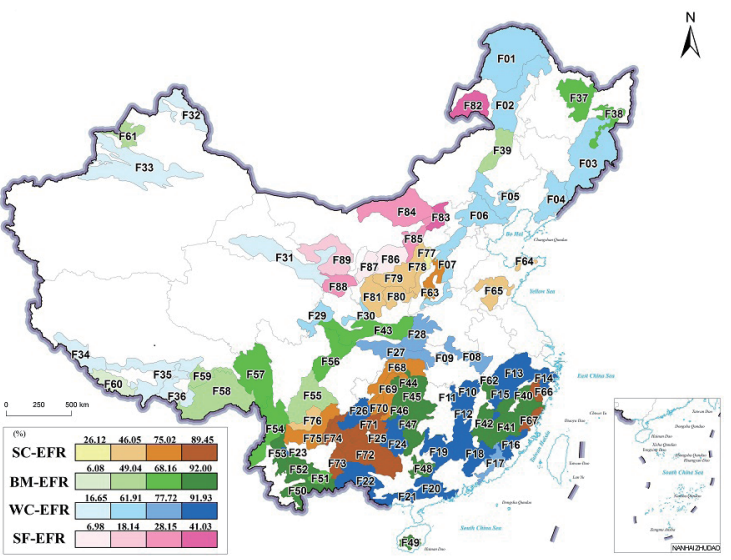

(d)

Fig. 4. (Color online) Forest ecosystem $C B V$ in China: (a) GPP, (b) NPP, (c) LAI, and (d) FVC.

arid shrubs dominated these areas. Additionally, these areas had rich floral and faunal diversity. The ecosystem has important functions in biodiversity protection, water conservation, and soil conservation, reflecting the optimum natural ecological background characteristics in China.

The humid and semi-humid temperate regions in central China are dominated by hills and mountains, with vegetation types of deciduous broad-leaved forests, coniferous forests, and hilly mountainous shrubs. In the forest ecosystem $C B V$, the ranges of GPP, NPP, LAI, and FVC were 2.67-4.19 and $1.54-2.16 \mathrm{kgC} / \mathrm{m}^{2}$ and $1.11-2.40$ and $54.76-74.71 \%$, respectively, in this area, except in loess hilly and gully regions.

In the humid cold and mid-temperate, and semi-humid mid-temperate areas in northeast China, cold temperate coniferous forests, mountain coniferous and broad-leaved mixed forests, and temperate coniferous and broad-leaved mixed forests were dominant, with high plant coverage and rich floral and faunal diversity. The ranges of GPP, NPP, LAI, and FVC for the forest ecosystem $C B V$ were $2.51-3.79$ and $1.44-2.05 \mathrm{kgC} / \mathrm{m}^{2}$ and $1.30-2.11$ and $61.56-71.50 \%$, respectively, in this area. 
The forest types in the arid and alpine areas of northwest China and Qinghai Tibet Plateau were mainly mountain coniferous forests, mountain shrubs, and forest grassland, with low vegetation productivity and coverage. The background GPP was $<2 \mathrm{kgC} / \mathrm{m}^{2}, \mathrm{NPP}$ was $<1 \mathrm{kgC} / \mathrm{m}^{2}$, LAI was generally $<1$, and $\mathrm{FVC}$ was $<50 \%$.

\subsubsection{Spatial characteristics of grassland ecosystem $C B V$}

$C B V$ of grassland ecosystems in China (Fig. 5) showed evident variations in the spatial characteristics. Alpine meadows in the humid, semi-arid, and cold plateau regions of China had high productivity. The ranges of GPP, NPP, LAI, and FVC values were 1.09-1.78 and $0.64-1.07 \mathrm{kgC} / \mathrm{m}^{2}$ and $0.49-0.69$ and $24.04-36.62 \%$, respectively, in $C B V$. All parameters were in the high-value areas of the National Grassland Ecological reference system.

Alpine and swamp meadows, mountain meadows, and desert grassland were distributed in the ecological function areas of semi-arid, semi-humid, and arid areas, respectively. The $C B V$ parameters of the grassland ecosystem were high, with the ranges of GPP, NPP, LAI, and FVC being $1.44-2.25$ and $0.57-1.32 \mathrm{kgC} / \mathrm{m}^{2}$ and $0.37-0.92$ and $19.87-41.94 \%$, respectively.

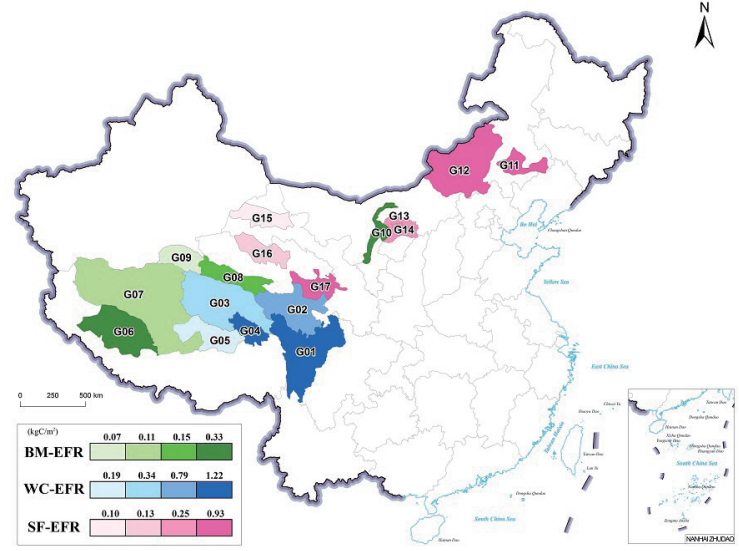

(a)

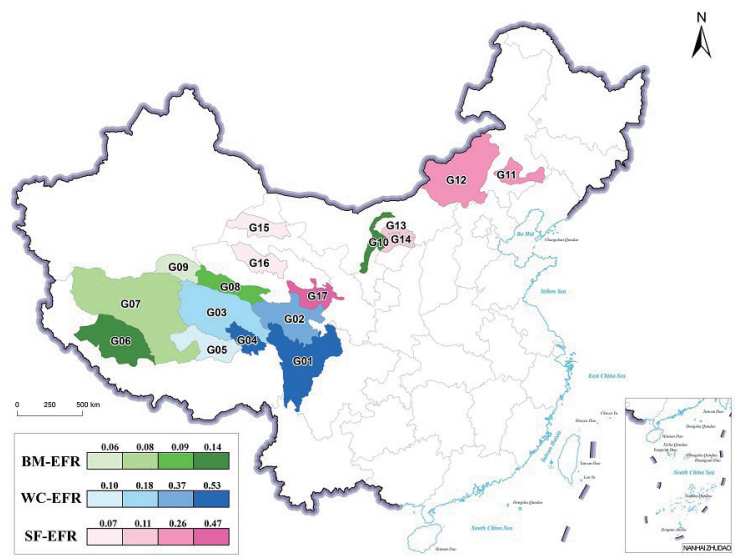

(c)

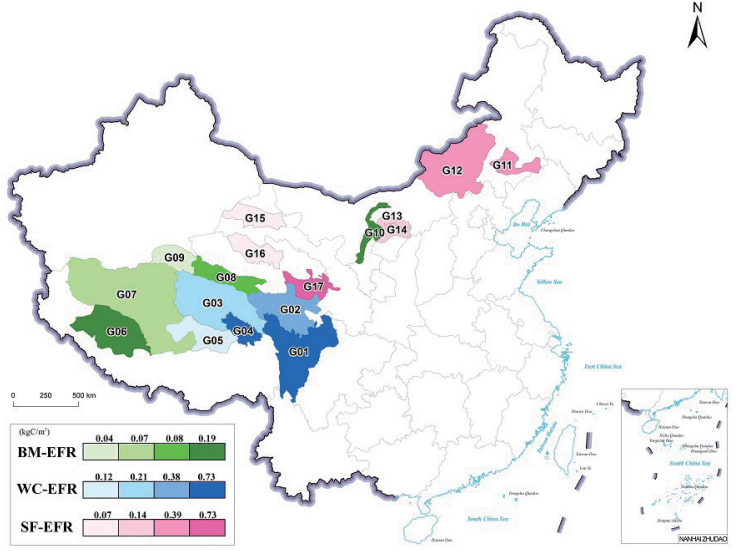

(b)

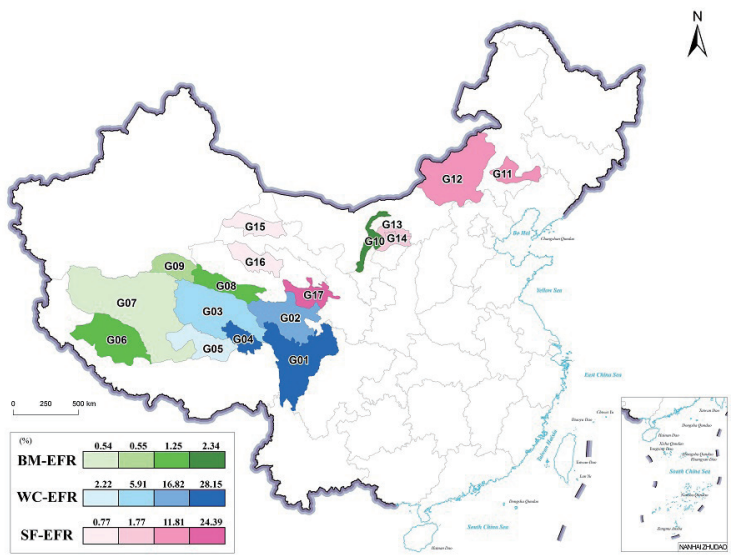

(d)

Fig. 5. (Color online) Grassland ecosystem $C B V$ in China: (a) GPP, (b) NPP, (c) LAI, and (d) FVC. 
The grassland in the western semi-arid cold plateau showed low vegetation productivity and coverage, with characteristics similar to those of alpine desert with the ranges of GPP, NPP, LAI, and FVC being $0.11-0.49$ and $0.07-0.29 \mathrm{kgC} / \mathrm{m}^{2}$ and $0.08-0.25$ and $1-9.60 \%$, respectively.

The natural ecosystem in the arid cold plateau and the arid and semi-arid temperate areas in China comprised mainly desert grassland. The grassland $C B V$ showed the lowest parameter values $\left(\mathrm{GPP}=0.07-0.34 \mathrm{kgC} / \mathrm{m}^{2}, \mathrm{NPP}=0.04-0.19 \mathrm{kgC} / \mathrm{m}^{2}, \mathrm{LAI}=0.05-0.13 \%\right.$, and $\left.\mathrm{FVC} \leq 2 \%\right)$.

\subsection{Spatial characteristics of $R B V$}

\subsubsection{Differences in $R B V$ between ecological functions}

$R B V$ differed in different types of ecological function regions (Fig. 6). In general, $R B V$ of forest ecosystems was higher than that of grassland. In the forest ecosystem, the $R B V$ parameters showed clear differences. LAI showed a higher recovery rate in the functions of water conservation, biodiversity protection, and soil conservation, among which the LAI recovery rate in biodiversity protection functional regions was the most significant; however, the other parameters in the three functional areas did not clearly differ. In the sand fixation ecological function regions, the $R B V$ parameters, except the LAI recovery rate, were significantly higher than those of the other three ecological function regions.

In the grassland $R B V$, the ecological function regions of wind prevention and sand fixation had the most significant restoration, and the $R B V$ parameters were significantly higher than those of other regions. $R B V$ of the biodiversity protection ecological function region was relatively low, and the recovery rate of FVC was the highest in the water conservation ecological function regions.

\subsubsection{Spatial characteristics of forest ecosystem $R B V$}

$R B V$ of forest ecosystems in China showed clear differences in the spatial characteristics (Fig. 7). The recovery rate of most forest ecosystem regions showed similar characteristics to the rapid recovery rate. The recovery rates of GPP, NPP, and LAI of the forest ecosystem $R B V$ were

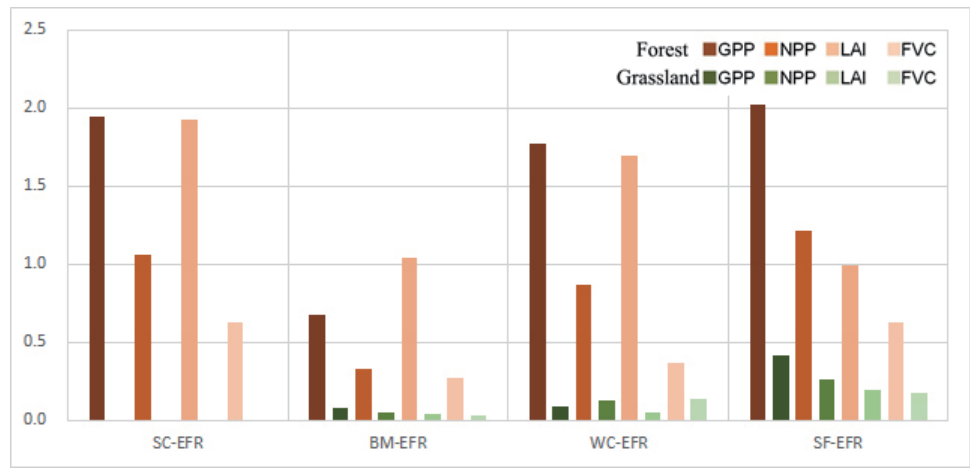

Fig. 6. (Color online) Differences in $R B V$ between the four types of ecological function regions. 


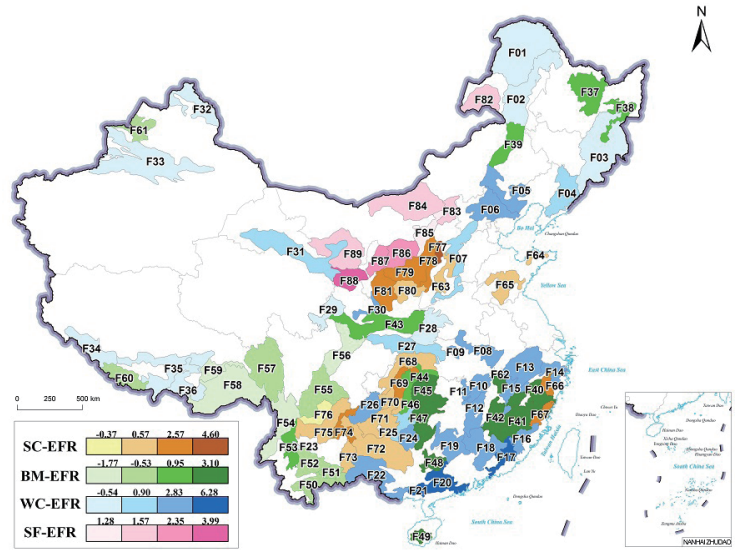

(a)

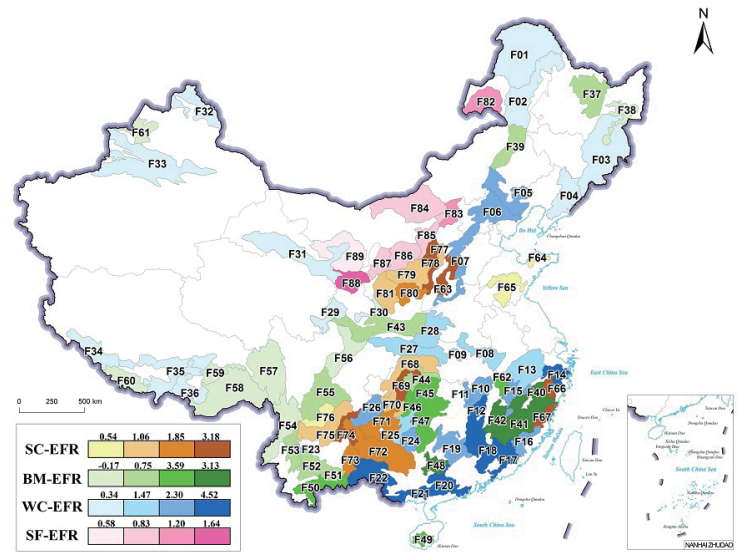

(c)

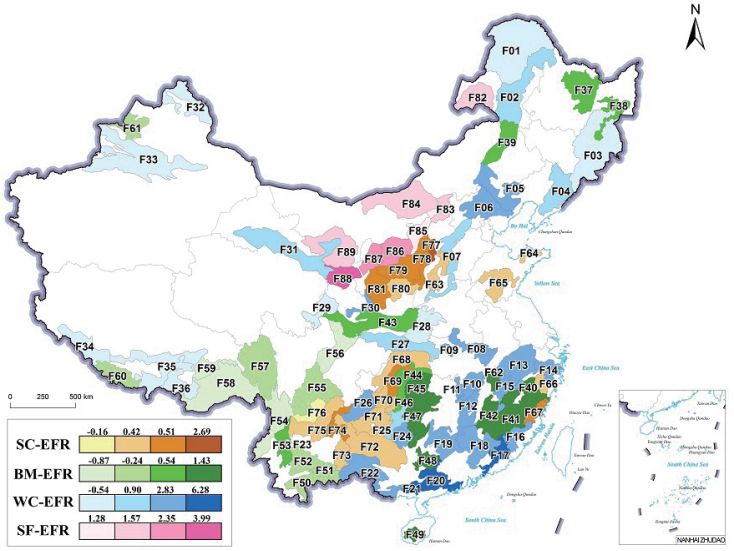

(b)

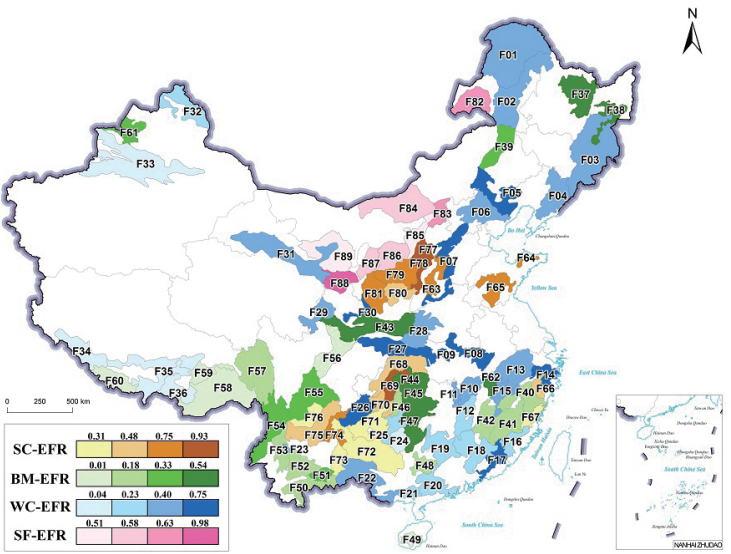

(d)

Fig. 7. (Color online) Forest ecosystem $R B V$ in China: (a) GPP, (b) NPP, (c) LAI, and (d) FVC.

high in the subtropical and tropical humid areas of southern China. Vegetation coverage in the humid and semi-humid temperate areas from central to northern China was significantly restored, especially in the loess gully area and the windbreak and sand fixation zones, which can be attributed to the ecological protection and restoration measures undertaken in these areas.

The vegetation ecological restoration characteristics for the functional areas in the northwest arid area, Qinghai Tibet Plateau, and the southwest karst area, including Western Junggar Basin and Altai Mountain in the northwest arid area, Upper and Middle Yarlung Zangbo River, North of Middle Himalayan, Snowy Mount-Nianta Weng Mount, Minshan Mount-Qionglai Mount, Southern Nianqing Tanggula Mountain, Shannan Area, and Northwest Yunnan Plateau in Qinghai Tibet Plateau, were not significant and showed a degradation trend. Additionally, similar behavior was observed in the ecological function areas of Southern Yunnan and Mengzi Yuanjiang Karst Plateau Canyon in the southwest karst area. 


\subsubsection{Spatial characteristics of grassland ecosystem $R B V$}

Clear differences were observed in the spatial characteristics of $R B V$ of the grassland ecosystem in China (Fig. 8). The productivity of the grassland ecosystem functional regions of Lancang River Source and Southern Qiangtang in northwest China and the south of Qinghai Tibet Plateau showed a downward trend, while the other ecological background regions showed recovery characteristics. The spatial characteristics of GPP, NPP, and LAI in the grassland RBV were similar - the recovery in the east, central, and north areas of Qinghai Tibet Plateau was significantly higher than in other regions, and the spatial characteristics of FVC differed marginally, in which the arid and semi-arid sandy land in central and northern China recovered rapidly.

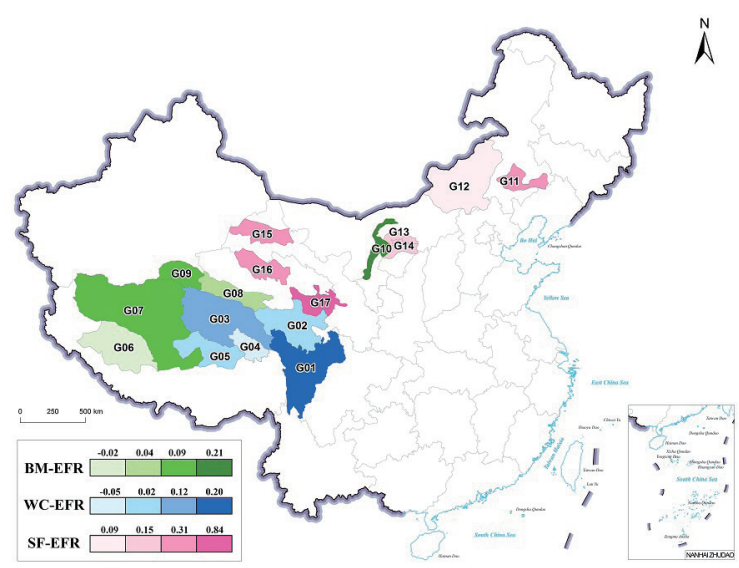

(a)

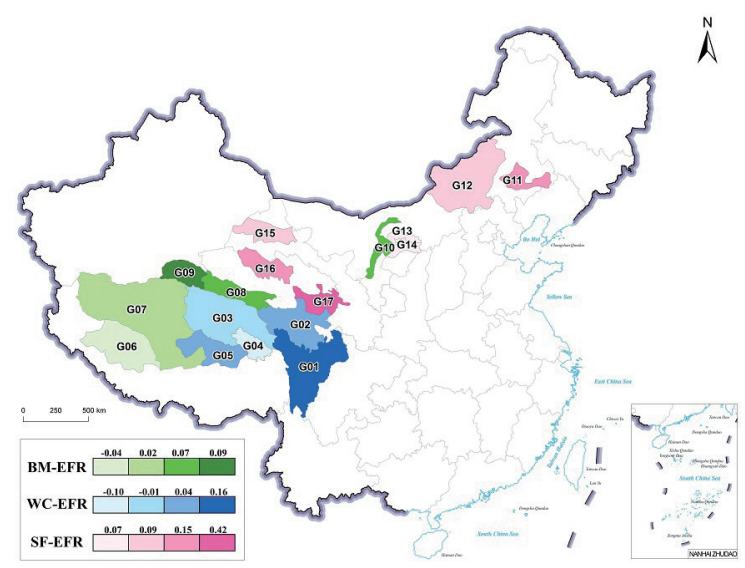

(c)

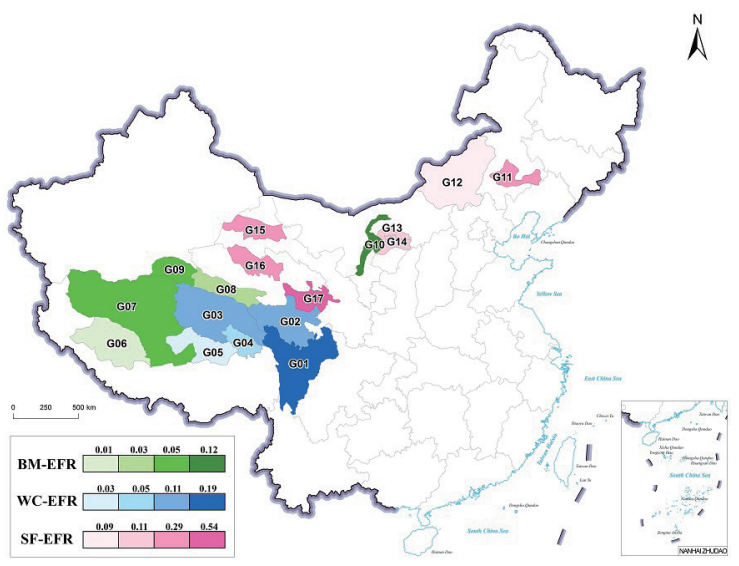

(b)

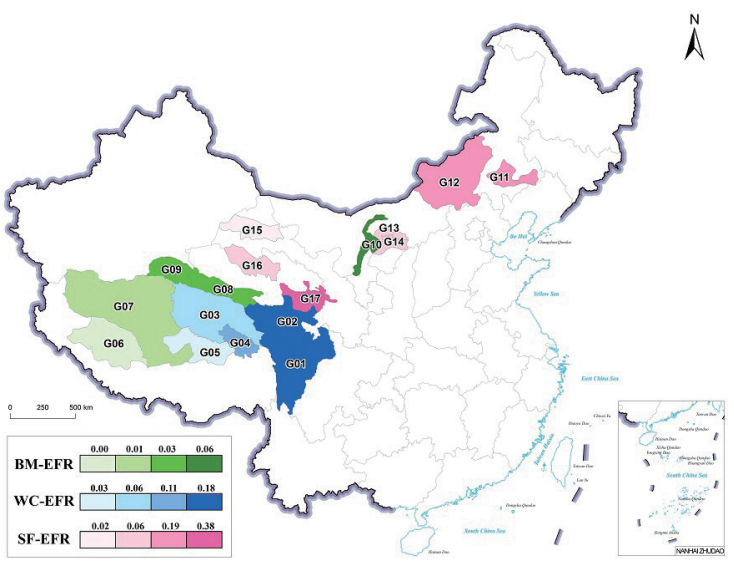

(d)

Fig. 8. (Color online) Grassland ecosystem RBV in China: (a) GPP, (b) NPP, (c) LAI, and (d) FVC. 


\subsection{Spatial characteristics of $S B V$}

\subsubsection{Differences in $S B V$ between ecological functions}

The differences in $S B V$ in different ecological function regions are shown in Fig. 9. In the forest ecosystem $S B V$, no clear difference in the ecosystem stability in each type of ecological function region was observed. The FVC in each region was stable, with the highest value in the ecological function region with water conservation. In contrast, the LAI of the soil conservation, biodiversity protection, and water conservation ecological function regions fluctuated significantly.

In the grassland $S B V$, the ecosystem stability of the ecological function regions with biodiversity protection was the highest. The values of vegetation ecosystem parameters in the water conservation and sand fixation function regions showed clear fluctuations, among which the fluctuation in the ecological function region with water conservation was the most significant.

\subsubsection{Spatial characteristics of forest ecosystem $S B V$}

$S B V$ of forest ecosystems in China showed evident differences in the spatial characteristics of the forest ecosystem (Fig. 10). Among the forest ecosystems in northwest China, Qinghai Tibet Plateau, and the southwest karst area, the stability of GPP, NPP, and LAI in $S B V$ was also unsatisfactory in Altai Mountain, Minshan Mount-Qionglai Mount, Northwest Yunnan Plateau, Southern Nianqing Tanggula Mountain, and Shannan Area, and the humid sub-thermal and thermal areas in the south, all of which showed evident ecosystem degradation trends. Except in northern China, the forest ecosystem $S B V$ in most regions was relatively stable.

\subsubsection{Spatial characteristics of grassland ecosystem $S B V$}

The differences in the spatial characteristics of the grassland ecosystem $S B V$ in China are shown in Fig. 11. Significant differences in the stability of background parameters were observed between Qinghai Tibet Plateau and the desert grassland in arid, semi-arid, and cold plateaus of

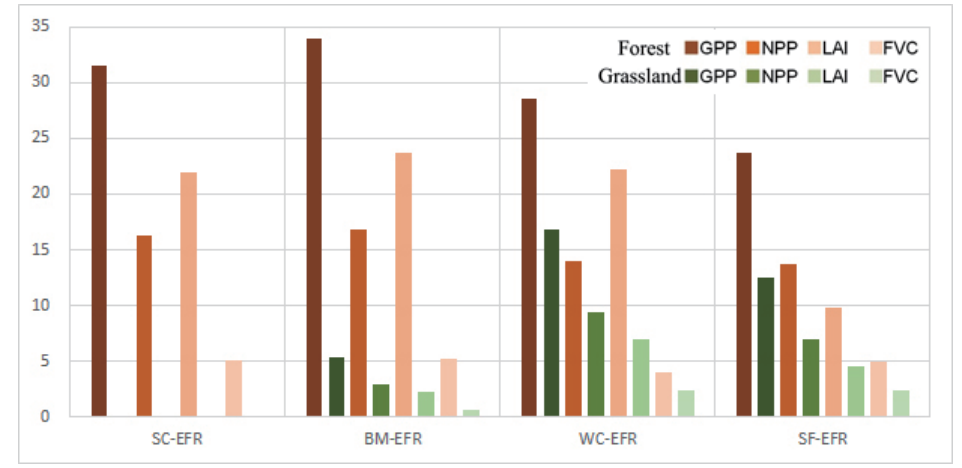

Fig. 9. (Color online) Differences in SBV between the four types of ecological function regions. 


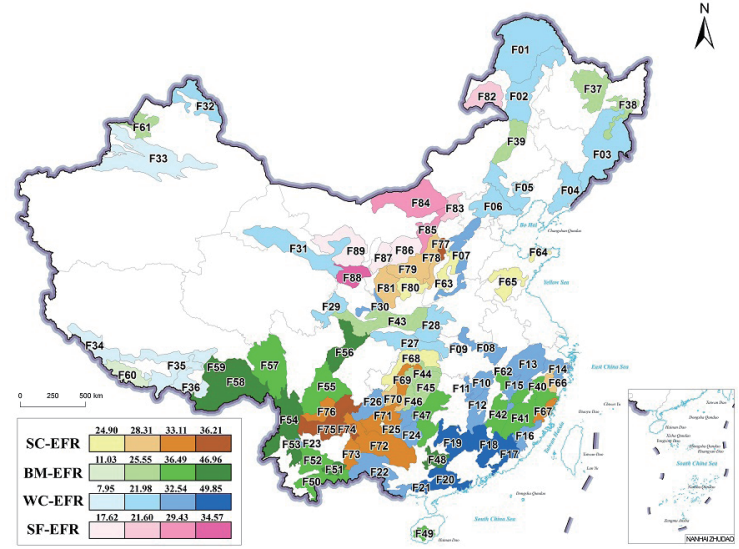

(a)

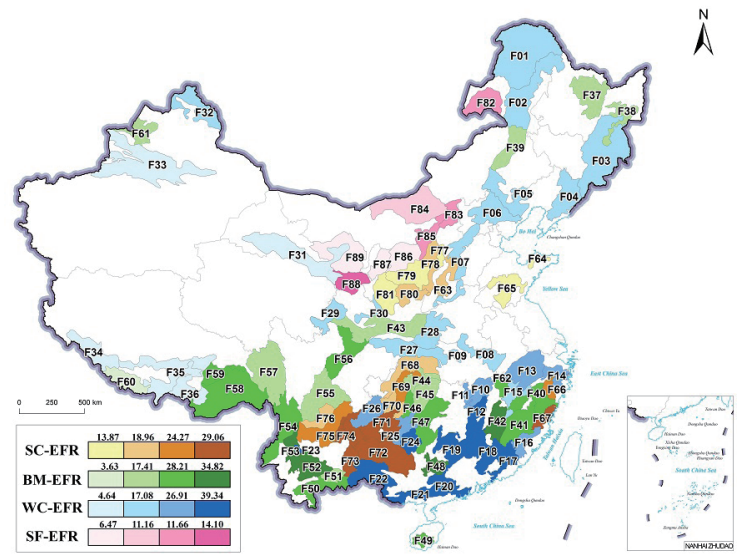

(c)

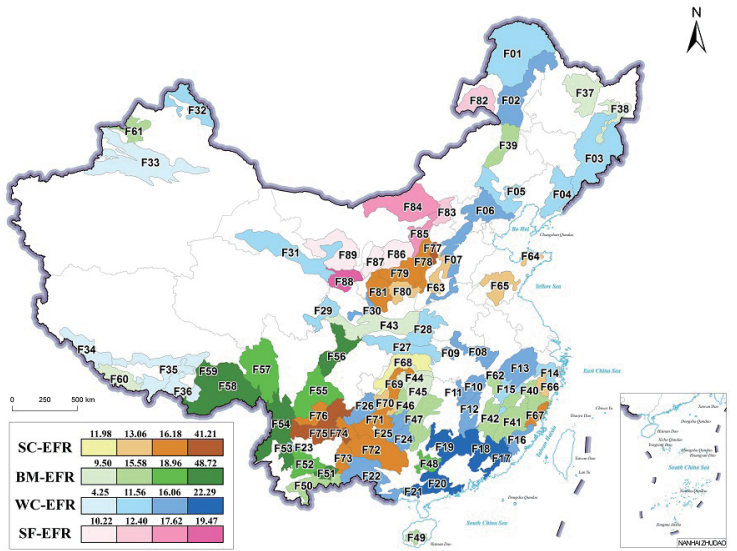

(b)

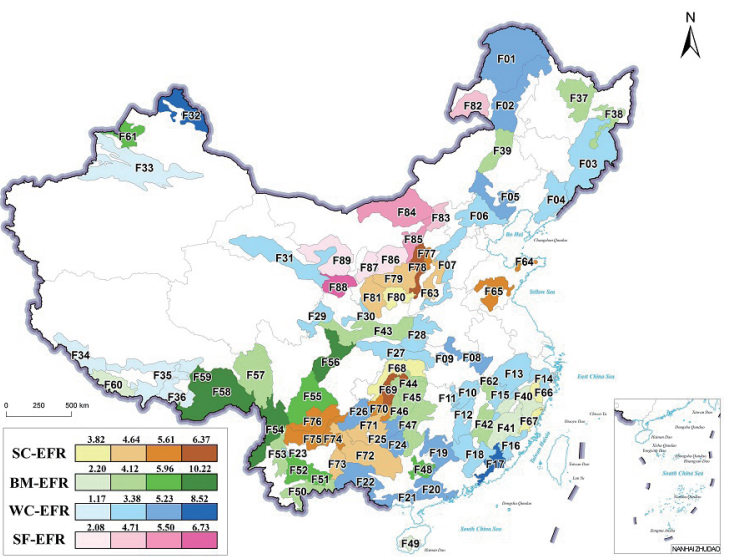

(d)

Fig. 10. (Color online) Forest ecosystem $S B V$ in China: (a) GPP, (b) NPP, (c) LAI, and (d) FVC.

northwest China. The stability background of grassland ecosystem functional areas, such as Northwest Sichuan, Yellow River Source, Lancang River Source, Horqin Sandy Land, Hunshandak Sandy Land, and Gonghe Basin, with high productivity and recovery rate showed certain fluctuations, which may be affected by changes in the natural conditions and by human interference.

\section{Discussion}

Despite the ecological importance of this study, several limitations of the study need to be further studied and discussed in future research.

(1) The natural ecological background constructed in this study is macroscopic and generalized; that is, the overall background of forest and grassland ecosystems in different ecological function areas was considered. The factors leading to changes in the parameters in individual regions due to climate change were not studied. Furthermore, in this study, the natural ecological background considered the national ecological function regions as the 


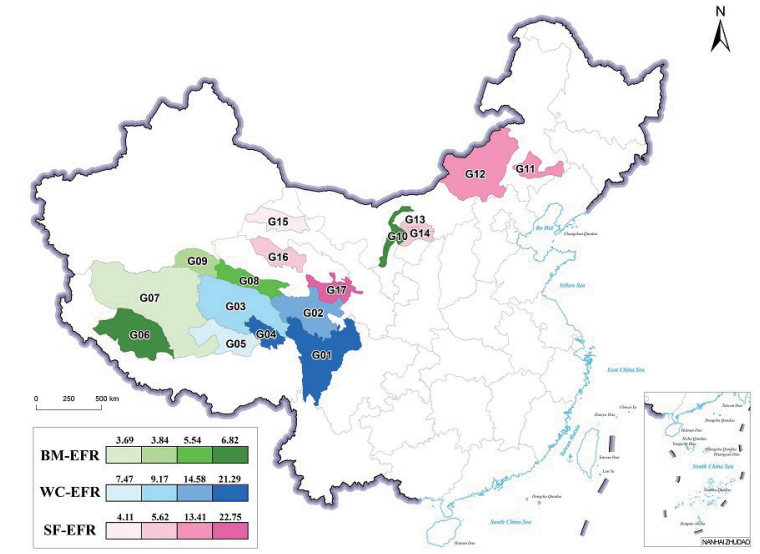

(a)

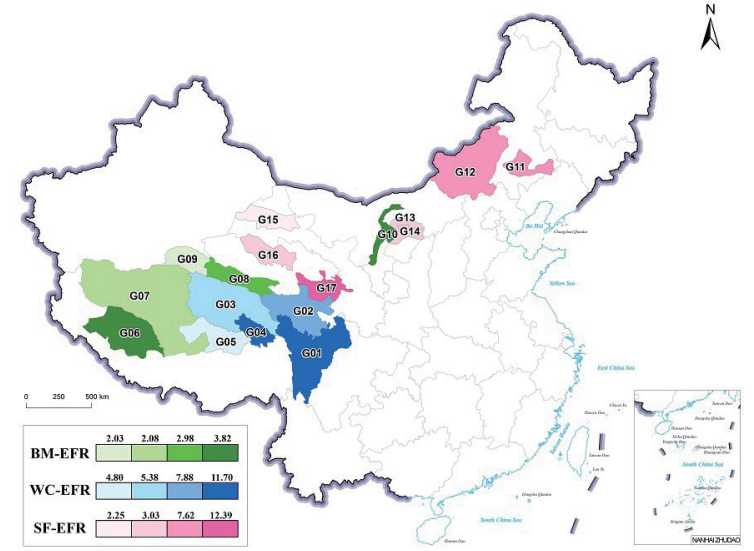

(b)

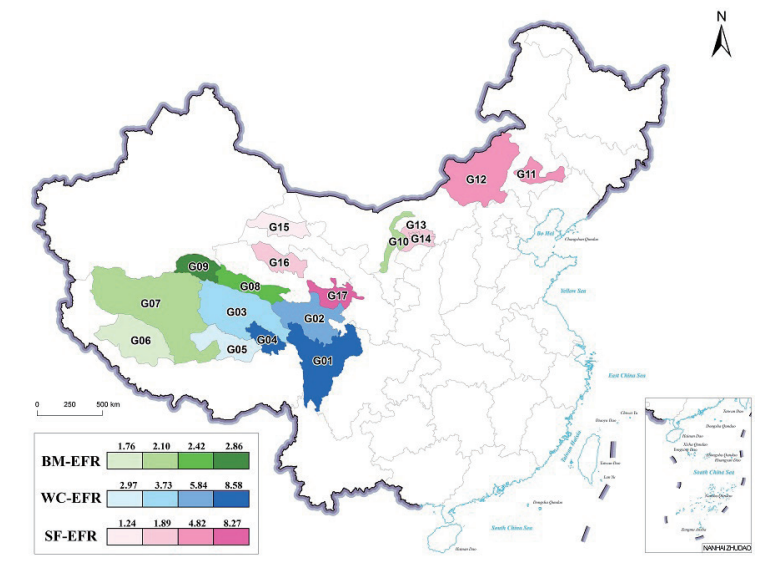

(c)

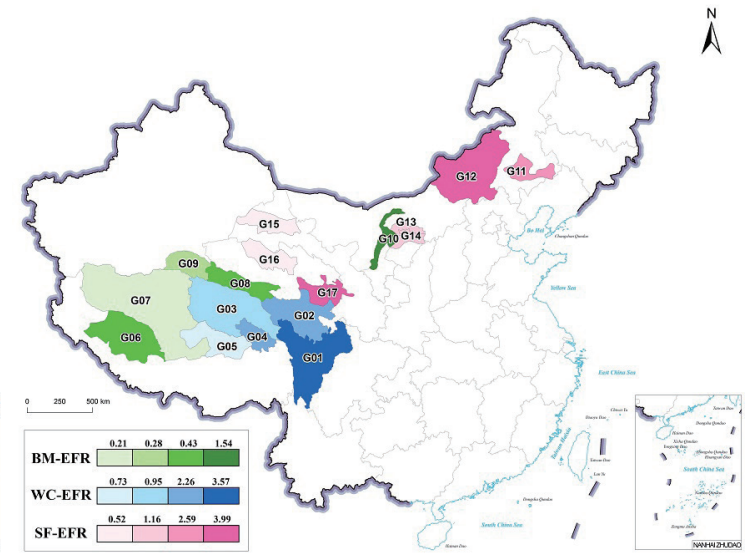

(d)

Fig. 11. (Color online) Grassland ecosystem $S B V$ in China: (a) GPP, (b) NPP, (c) LAI, and (d) FVC.

reference for spatial division; however, the influence of climate differences caused by latitude, atmospheric circulation, and topographic fluctuation is fully considered. Moreover, the natural ecological background eliminated the human influence by considering the national nature reserves as the parameter value extraction range.

(2) The $C B V, R B V$, and $S B V$ parameters of background values were based on the vegetation parameters of the 20-year continuous series dynamic data. Although extending the time range of parameters can improve the accuracy of the background value, the 20-year series data can objectively reflect the growth and change of vegetation when trend prediction was not the aim.

(3) The ecological background was established according to the boundaries of key national nature reserves. The scientific nature and rationality of the boundary of each nature reserve directly affected the accuracy of the background value. If the investigation data, such as the characteristics of the ecosystem landscape pattern, the ecosystem service characteristics, and the monitoring results of human activities, of the ecosystem status of the nature reserve are effectively used as supplements, further optimization and correction of the ecological 
background area can be achieved, and the accuracy of the ecological background will be considerably improved.

\section{Conclusions}

By considering the authenticity of nature reserve ecosystems and the spatial differentiation of vegetation ecosystems, this study established a natural ecological background for a vegetation identification method using land vegetation parameters obtained by remote sensing technology. Additionally, based on the geographical units, coupled with the overlap and inclusion relationships between the ecological function regions and national nature reserves, the spatial basis of the natural ecological background, that is, the "ecological homogeneous area", was constructed. Subsequently, the vegetation ecological parameters $(C B V, R B V$, and $S B V)$ were identified using the vegetation characteristics of the nature reserves as the background, based on the time dimension of "Recovery-Stability" and the type dimension of "Forest and Grassland" of vegetation.

The main conclusions are as follows:

(1) The spatial difference in $C B V$ was significant, with the forest and grassland ecosystem $C B V$ reflecting the characteristics of the regional hydrothermal conditions. Humid and hightemperature areas corresponded to high- $C B V$ areas, arid and low-temperature areas corresponded to low- $C B V$ areas, while semi-arid and semi-humid areas showed intermediate $C B V$ values. This indicates that $C B V$ increased from arid to humid high-temperature areas, consistent with the spatial differentiation characteristics of natural ecosystems in China.

(2) The spatial difference in $R B V$ was significant, with regions with high $R B V$ distributed in the loess hilly areas, northern arid areas, and in areas with the main ecological function of sand fixation. The spatial distribution characteristics of the areas with a high background value of the vegetation coverage restoration rate were evident, or related to the ecological protection and restoration measures undertaken in the area. Some functional areas with low $R B V$ were located in the northwest arid area, Qinghai Tibet Plateau, and southwest karst area, and the productivity of land vegetation in these regions showed a degradation trend. This was consistent with the ecological environmental protection policy in China.

(3) $S B V$ in some regions clearly reflected the spatial differences, which were mainly reflected in the poor stability of the forest ecosystem in Qinghai Tibet Plateau and the southwest karst area. In grassland ecosystems, regions with high productivity and recovery rates in Qinghai Tibet Plateau and the northwest arid and semi-arid cold plateau showed significant volatility in $S B V$. This result was in good agreement with the spatial differences in the natural ecological environment vulnerability and sensitivity to external environmental changes in China.

The method of using ecological background values based on the common terrestrial vegetation ecosystem in the national nature reserves of China is scientifically advanced, and can be used as a reference for evaluating the effectiveness of protection and restoration of terrestrial ecosystems in China. 


\section{Acknowledgments}

This research was supported by the National Key R\&D Program of China (Grant No. 2017YFC0506506) and the Regular Remote Sensing Survey and Assessment of National Ecological Status of China (Grant No. 22111101006001).

\section{References}

1 P. Ekins, J. Gupta, and P. Boileau: Global Environment Outlook-GEO-6: Healthy Planet, Healthy People (Cambridge University Press., Cambridge, 2019).

2 R. C. Gardner and M. Finlayson: Proc. 2018. Secretariat of the Ramsar Convention (2018).

3 J. J. McCarthy, O. F. Canziani, N. A. Leary, D. J. Dokken, and K. S. White: Climate Change 2001: Impacts, Adaptation, and Vulnerability (Cambridge University Press, Cambridge, 2001).

4 T. Shugart, T. M. Smith, T. M. Smith, T. Smith, H. Shugart, and F. Woodward: Plant Functional Types: Their Relevance to Ecosystem Properties and Global Change (Cambridge University Press, Cambridge, 1997).

5 M. L. Hillstrom, J. J. Couture, T. D. Meehan, E. B. Mondor, and R. L. Lindroth: Proc. 2010 Esa Convention (2010).

6 G. H. Liu and B. J. Fu: J. Nat. Resour. 16 (2001) 71

7 D. Yu, H. M. Yan, W. P. Du, and Y. F. Hu: J. Nat. Resour. 34 (2019) 1093. https://doi.org/10.31497/ zrzyxb.20190515

8 B. Guo, W. H. Kong, and L. Jiang: J. Nat. Resour. 33 (2018) 412. https://doi.org/10.11849/zrzyxb.20170068

9 China has launched 16 ecological restoration projects, covering $63 \%$ of the land: http://news.sciencenet.cn/ htmlnews/2012/12/273375.shtm (accessed December 2012).

10 P. Hou, J. X. GAO, C. Yan, Z. Jun, R. L. Xiao, W. G. Zhang, C. X. Sun, Y. C. Wang, and H. Jing: Acta Ecol. Sin. 41 (2021) 1656. https://doi.org/10.5846/stxb202002260345

11 G. Wu, H. M. Zhao, and C. X. Wang: Acta Ecol. Sin. 39 (2019) 8685. https://doi.org/10.5846/stxb201911212525

12 Z. G. Wang: Soil Water Conserv. China. 10 (2003) 4.

13 S. L. Peng and P. Zhao: Chin. J. Appl. Ecol. 11 (2000) 799. https://doi.org/doi:10.1007/s11769-000-0008-7

14 C. Chi, T. Park, X. Wang, S. Piao, B. Xu, R. K. Chaturvedi, R. Fuchs, V. Brovkin, P. Ciais, and R. Fensholt: Nat. Sustainability 2 (2019) 122. https://doi.org/10.1038/s41893-019-0220-7

15 Protected Planet Report 2018 (Cambridge: UNEP-WCMC, IUCN and NGS, 2018).

16 B. Guan, G. F. Cui, and Z. J. Piao: World For. Res. 25 (2012) 40. https://doi.org/10.1007/s11783-011-0280-Z

17 Y. Y. Yan, J. Deng, and Z. Q. Zhang: Chin. J. Ecol. 33 (2014) 1128. https://doi.org/10.13292 j.1000-4890.2014.0120

18 Y. L. Zhang, Z. J. Hu, W. Qi, X. Wu, W. Q. Bai, L. H. Li, M. J. Ding, L. Liu, C. X. Wang, and D. Zheng: Acta Geographica Sinica 26 (2016) 27. https://doi.org/10.1007/s11442-016-1252-9

19 J. Zhai, P. Hou, W. Cao, M. Yang, M. Y. Cai, and J. Li: J. Geog. Sci. 28 (2018) 415. https://doi.org/10.1007/ s11442-018-1481-1

20 Z. S. LI, L. Yang, G. L. Wang, J. Hou, Z. B. Xin, G. H. Liu, and B. J. Fu: Acta Ecol. Sin. 39 (2019) 7398. https:// doi.org/10.5846/stxb201909021821

21 T. Li, Y. Luo, and Y. H. Lv: Environ. Ecol. 1 (2019) 80.

22 Q. Q. Zhao: Vegetation Restoration Status and Its Relationship with Runoff and Sediment Variation in Typical Basins of the Loess Plateau in Northern Shaanxi Province (Northwest A \& F University, Xianyang, 2019).

23 X. J. Wen: Spatial and Temporal Changes of Vegetaion Coverage Response to SLCP in the Middle and Upper Reaches of the Yellow River (Northwest A \& F University, Xianyang, 2019).

24 H. Chen: Spatial and Temporal Changes of Soil Erosion and Its Driving Factors before and after the "Grain for Green" Project in the Loess Plateau (Northwest A \& F University, Xianyang, 2019).

25 D. M. Chen, N. N. Zhang, L. Liu, B. Zhong, Z. L. Tang, W. C. Yan, X. L. Ying, and G. Sun: Chin. J. Appl. Environ. Biol. 22 (2016) 573. https://doi.org/10.3724/SP.J.1145.2016.05007

26 P. Hou, J. X. Gao, H. W. Wan, P. R. Shi, Y. C. Wang, and C. X. Sun: Environ. Ecol. 3 (2021) 1.

27 Z. J. Li: Ecology (Corporate Profile of China Science Publishing \& Media Ltd., Bei Jing, 2014).

28 U. E. P. Agency: Guidance for Comparing Background and Chemical Concentrations in Soil for CERCLE Sites, Washington DC: Office of Emergency and Remedial Response (2002).

29 T. B. Chen, Y. M. Zheng, H. Chen, and G. D. Zheng: Environ. Sci. 25 (2004) 117. https://doi.org/10.13227/j. hjkx.2004.01.026 
30 M. Chen, L. Q. Ma, C. G. Hoogeweg, and W. G. Harris: Environ. Forensics. 2 (2001) 117. https://doi.org/10.1006/ enfo.2001.0050

31 L. Q. Ma, F. Tan, and W. G. Harris: J. Environ. Qual. 26 (1997) 769. https://doi.org/10.2134/ jeq1997.00472425002600030025x

32 China National Environmental Monitoring Centre: Background Values of Soil Elements in China (China Environmental Science Press, Beijing, 1990).

33 A. Molinari, L. Guadagnini, M. Marcaccio, and A. Guadagnini: Sci. Total Environ. 425 (2012) 9. https://doi. org/10.1016/j.scitotenv.2012.03.015

34 F. S. Wei, J. S. Chen, Y. Y. Wu, and C. J. Zhen: Chin. J. Environ. Sci. 12 (1991) 12. https://doi.org/10.13227/j. hjkx.1991.04.005

35 L. Yang and Hasibilige: Inner Mongolia Sci. Technol. Econ. 3 (2015) 68.

36 G. Liu, P. Tang, Z. Q. Cai, T. T. Wang, and J. F. Xu: Spectrosc. Spect. Anal. 35 (2015) 2970. https://doi. org/10.3964/j.issn.1000-0593(2015)10-2970-07

37 Y. F. Zhang and Z. Y. Ren: J. Soil Water Conserv. 5 (2006) 166. https://doi.org/10.13870/j.cnki. stbcxb.2006.05.041

38 G. Y. Ren: Acta Ecol. Sin. 24 (2004) 1287.

39 X. S. Zhang: Chin. J. Plant Ecol. 18 (1994) 1.

40 M. H. Li, K. Norbert, and J. Yang: Progress Geogr. 21 (2002) 450.

41 Y. P. Lu, J. S. Du, S. J. Liang, and J. J. Yuan: Chin. J. Ecol. 24 (2005) 53.

42 R. B. Myneni, C. D. Keeling, C. J. Tucker, G. Asrar, and R. R. Nemani: Nature 386 (1997) 698. https://doi. org $/ 10.1038 / 386698 \mathrm{a} 0$

43 P. Wang, R. Sun, J. Hu, Q. Zhu, Y. Zhou, L. Li, and J. M. Chen: J. Environ. Manage. 85 (2007) 607. https://doi. org/10.1016/j.jenvman.2006.08.017

44 M. Rossini, S. Cogliati, M. Meroni, M. Migliavacca, M. Galvagno, L. Busetto, E. Cremonese, T. Julitta, C. Siniscalco, and U. Morra di Cella: Biogeosciences 9 (2012) 2565. https://doi.org/10.5194/bg-9-2565-2012

45 J. Liu, O. J. Sun, H. Jin, Z. Zhou, and X. Han: J. Plant Ecol. 4 (2011) 302. https://doi.org/10.1093/jpe/rtr019

46 N. C. Parazoo, K. Bowman, J. B. Fisher, C. Frankenberg, D. B. Jones, A. Cescatti, Ó. Pérez-Priego, G. Wohlfahrt, and L. Montagnani: Global Change Biol. 20 (2014) 3103. https://doi.org/info:doi/10.1111/gcb.12652

47 B. Igbpihdp: Land-use and Landcover Change Science Research Plan (1995).

48 J. Liu, Z. Zhang, X. Xu, W. Kuang, W. Zhou, S. Zhang, R. Li, C. Yan, D. Yu, and S. Wu: J. Geogr. Sci. 20 (2010) 483. https://doi.org/10.1007/s11442-010-0483-4

49 Regulations of the People's Republic of China on Natural Reserves: https://www.gov.cn/ (accessed September 2011).

501276 Nature Reserves Have Been Built in China: https://www.gmw.cn/01gmrb/2001-02/02/ GB/02\%5E18680\%5E0\%5EGMA2-007.htm (accessed February 2001).

51 In the past 70 years, China has established 2750 nature reserves: https://www.mee.gov.cn/ (accessed September 2019).

52 L. Liu, Y. Zhang, W. Bai, J. Yan, M. Ding, Z. Shen, S. Li, and D. Zheng: J. Geogr. Sci. 16 (2006) 131. https://doi. org/10.3321/j.issn:0375-5444.2006.01.001

53 J. Evans and R. Geerken: J. Arid Environ. 57 (2004) 535. https://doi.org/10.1016/S0140-1963(03)00121-6

54 D. A. Stow, A. Hope, D. McGuire, D. Verbyla, J. Gamon, F. Huemmrich, S. Houston, C. Racine, M. Sturm, and K. Tape: Remote Sens. Environ. 89 (2004) 281. https://doi.org/10.1016/j.rse.2003.10.018

55 National Ecological Function Regionalization (revised version): https://www.mee.gov.cn/gkml/hbb/ bgg/201511/t20151126 317777.htm (accessed November 2015).

56 S. Liang, W. Yuan, Q. Xiao, X. Zhao, M. Ma, X. Zeng, S. Liu, and X. Cheng: Bull. Chin. Acad. Sci. 28 (2013) 122.

57 Bulletin on China's Ecological Environment in 2020 (China: Ministry of Ecology and Environment, PRC, 2021).

58 China's Multi-Period Land Use Land Cover Remote Sensing Monitoring Dataset: http://www.resdc.cn/ (accessed July 2018). 


\section{About the Authors}

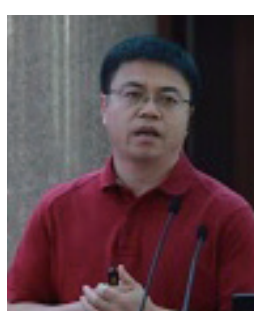

Peng Hou received his Ph.D. degree from College of Resource Science and Engineering of Beijing Normal University. He is currently a senior engineer in Satellite Application Center for Ecology and Environment, Ministry of Ecology and Environment of People's Republic of China. He is mainly engaged in remote sensing, ecological protection, and assessment research. (houpcy@163.com)

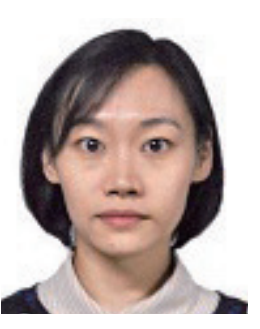

Yan Chen received her M.S. degree in geographical science from Peking University College of Urban and Environmental Sciences. She is mainly engaged in ecological remote sensing monitoring and evaluation. (chenyan30033@163.com)

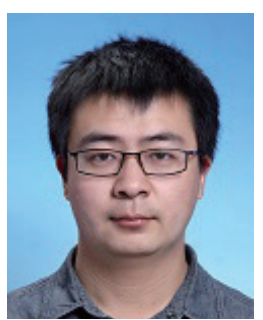

Jun Zhai received his Ph.D. degree from the Institute of Geographical Sciences and Natural Resources Research. He is currently a senior engineer in Satellite Application Center for Ecology and Environment, Ministry of Ecology and Environment of People's Republic of China. He is mainly engaged in satellite remote sensing and climate change research. (zhaijunsec@163.com)

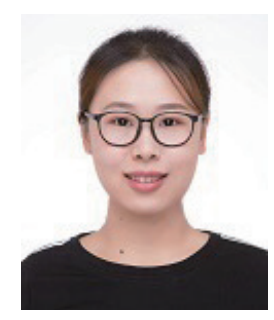

Jing Hou received her master's degree in ecology from Ningxia University in 2016. She is currently an engineer in Satellite Application Center for Ecology and Environment, Ministry of Ecology and Environment of People's Republic of China. Her research interests include the application of remote sensing data to ecological assessment. (weinigod1989@163.com)

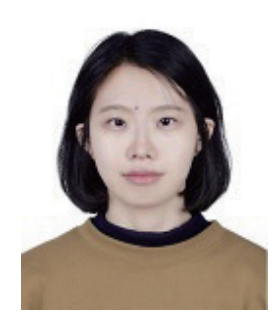

Min Yang received her M.Agr. degree in forestry from Southwest Forestry University in 2014. She is currently an engineer in Satellite Application Center for Ecology and Environment, Ministry of Ecology and Environment of People's Republic of China. Her research interests include ecological monitoring and evaluation using remote sensing data. (yangminsec@126.com) 


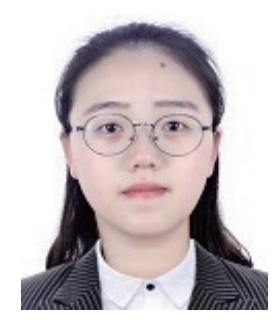

Diandian Jin received her B.S. degree in geographic information systems from Henan University of Economics and Law in 2016 and her M.S. degree in environmental engineering from Capital Normal University. She is currently an engineer in Satellite Application Center for Ecology and Environment, Ministry of Ecology and Environment of People's Republic of China. Her research interests include remote sensing monitoring and assessment of ecological conditions. (jin_diandian@163.com)

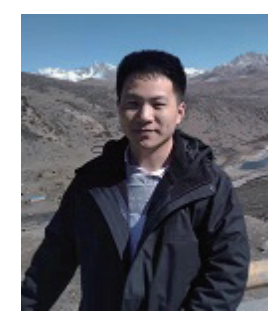

Hanshou Zhu received his master's degree in cartography and geographic information systems from Chongqing Normal University. He is mainly engaged in ecological remote sensing monitoring and evaluation. (zhuhanshoucq@163.com)

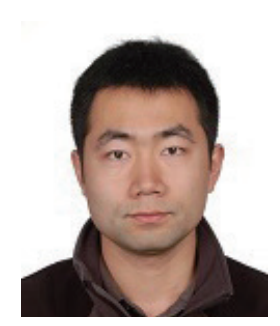

Haifeng Gao received his Ph.D. degree in environmental ecology from Beijing Normal University, Beijing, China, in 2013. From 2013 to 2019, he did postdoctoral research in Institute of Tibetan Plateau Research, Chinese Academy of Sciences. He is currently an associate research fellow in Satellite Application Center for Ecology and Environment, Ministry of Ecology and Environment of People's Republic of China. His research interests include the application of remote sensing data to cryosphere and ecological assessment. (gaohf03@hotmail.com)

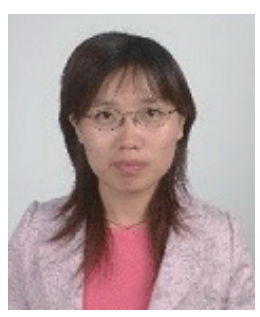

Huawei Wan received her Ph.D. degree from Beijing Normal University, Beijing, China. Currently, she is a research scientist in Satellite Application Center for Ecology and Environment, Ministry of Ecology and Environment, Beijing, China. Her research interests include quantitative parameter reversion, and ecosystem and biodiversity assessment based on remote sensing. (livelyhw@163.com)

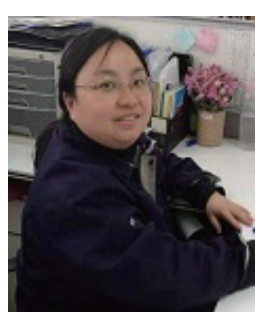

Zhuo Fu received her Ph.D. degree from Beijing Normal University. She is a senior engineer in Satellite Application Center for Ecology and Environment, Ministry of Ecology and Environment of People's Republic of China. Her research field is remote sensing monitoring and assessment of nature reserves. (fuzhuo@126.com) 